\title{
Importance of the Size of Adenomatous Polyps in Determining Appropriate Colonoscopic Surveillance Intervals
}

\author{
Hoon Sup Koo and Kyu Chan Huh \\ Division of Gastroenterology, Department of Internal Medicine, Konyang University College of Medicine, Daejeon, Korea
}

See "Mis-sizing of Adenomatous Polyps Is Common among Endoscopists and Impacts Colorectal Cancer Screening Recommendations" by Thu Pham, Aung Bajaj, Lorela Berberi, et al., on page 485-490.

Detection and removal of adenomatous polyps may prevent the development of colon cancer and reduce cancer-related mortality. ${ }^{1}$ Screening and surveillance are important based on evidence showing that interval examinations prevent interval cancers and cancer-related mortality. Post-polypectomy surveillance colonoscopy is crucial in preventing advanced adenoma and cancer.

The British Society of Gastroenterology updated their 2002 surveillance guidelines in 2010. The guidelines divided patients into 3 groups according to the following risk stratification: low risk (1-2 adenomas $<10 \mathrm{~mm}$ ), intermediate risk (3-4 small adenomas or 1 adenoma $\geq 10 \mathrm{~mm}$ ), and high risk ( $>5$ small adenomas or $\geq 3$ adenomas with at least 1 being $\geq 10$ $\mathrm{mm}){ }^{2}$ According to guidelines in the United States, patients who have only 1 or 2 small adenomas (low-grade adenoma) $<10 \mathrm{~mm}$ in size are recommended to have a 5-10 year interval between polypectomies, and those who have several $(<9)$ small adenomas (low-grade dysplasia) $<10 \mathrm{~mm}$ in size are recommended to have a 3-year interval between polypectomies. Patients with many adenomas ( $>10)$, those with 1 or more adenoma $\geq 10 \mathrm{~mm}$ in size, or those with high-grade dysplasia

Received: August 18, 2018 Accepted: September 12, 2018

Correspondence: Kyu Chan Huh

Division of Gastroenterology, Department of Internal Medicine, Konyang University College of Medicine, 158 Gwanjeodong-ro, Seo-gu, Daejeon 35365, Korea Tel: +82-42-600-9104, Fax: +82-42-9058, E-mail: kchuh2020@hanmail.net ORCID: https://orcid.org/0000-0003-3746-8419

(cc) This is an Open Access article distributed under the terms of the Creative Commons Attribution Non-Commercial License (http://creativecommons.org/ licenses/by-nc/3.0) which permits unrestricted non-commercial use, distribution, and reproduction in any medium, provided the original work is properly cited. are recommended to undergo a more intensive surveillance strategy. $^{3}$

The surveillance colonoscopy interval is based on risk stratification according to the number of adenomas, maximum size of polyps, and histopathologic findings of all resected lesions. ${ }^{2-5}$ Among the 3 risk stratification factors, polyp size is the most subjective factor. Generally, polyp size is visually estimated by endoscopists during colonoscopy; therefore, there is a possibility of incorrect size estimation. Since the appropriate timing for subsequent colonoscopy surveillance is largely reliant on the accuracy of polyp size estimation during colonoscopy, accurate measurement is crucial. Studies conducted to date on the measurement of polyp size have shown both, overestimated $^{6-8}$ and underestimated ${ }^{9-11}$ results.

Overestimation of the size of adenomatous polyps may result in a short surveillance interval, which requires patients to undergo surveillance colonoscopy more frequently. More frequent surveillance colonoscopy causes some problems. Colonoscopy is an invasive procedure with a small but significant risk of major complications, either from perforation (2\% with excision and $0.06 \%$ without excision) or from post-polypectomy bleeding $\left(0.2 \%-2.7 \%\right.$, depending on the lesion size). ${ }^{12-14}$ When surveillance colonoscopy is performed frequently, a heavy burden is conferred on the endoscopy services, leading to considerable medical expense.

In the current issue of Clinical Endoscopy, Pham et al. investigated the accuracy of visual estimation of the size of small adenomatous polyps ( $>6 \mathrm{~mm}$ ) by endoscopists, by comparing the visual estimation with the pathologic measurements of the same polyps. ${ }^{15}$ The study proved how mis-sizing of adeno- 
matous polyp influences the surveillance interval.

Although it was a retrospective study, it presented some highly remarkable and valuable results; however, there are also some factors that must be considered.

First, the authors reported that adenomatous polyps were clinically mis-sized in $56.6 \%$ of the cases, with a considerable variation in the sizing of polyps reported by endoscopists. In their analysis, $55 \%$ of the polyps were overestimated, whereas $1.6 \%$ of the polyps were underestimated with respect to size. According to the article, $18 \%$ of all adenomas reviewed resulted in inappropriate surveillance recommendations. In most mis-sizing cases, the pathologic size of the polyps was smaller than their endoscopically estimated size $(9.3 \mathrm{~mm}$ vs. $4.9 \mathrm{~mm}$ ), indicating overestimation of the polyp size during endoscopic evaluation. From the result, $22.4 \%$ of the patients whose polyps were mis-sized received an inadequate surveillance interval. On the basis of these results, it can be speculated that colonoscopy was frequently performed however, unfortunately, the reasons were not indicated. Moreover, the same question remains for $10 \%$ of the non-mis-sizing cases, as inappropriate surveillance was also recommended for them.

Among 6 endoscopists, 3 mis-sized $60 \%$ of the polyps and the other 3 mis-sized $<40 \%$ of the polyps. It is not known whether the discrepancy between the 2 groups is due to the different method or different colonoscopic equipment used for polyp sizing.

Second, the accurate assessment of polyp size during colonoscopy is difficult and challenging; therefore, it is also important to use a method that correctly measures the polyp size.

In real clinical settings, the following 3 methods are used for measuring the size of colon polyps: visual estimation, use of biopsy forceps, and use of a calibrated hood or probe. ${ }^{16,17}$ Measurement of polyp size is difficult even with the use of several instruments. In addition, an inter-observer difference exists. The discrepancy may be due to differences in visual estimation among endoscopists. Even when instruments are used, it is still difficult to align the forceps in the direction of the actual diameter of the polyps. The morphology of the polyp also contributes to the incorrect measurement of its size. ${ }^{7}$ In this study, about $57 \%$ of the mis-sized group were sessile polyps; therefore, it can be assumed that mis-sizing can also be dependent on the shape of the polyp.

Several problems must be overcome to obtain a precise measurement of the size of the polyps. When measuring the size of the polyps, there are some restrictions regarding the instruments that can be used for this purpose. In addition, the actual measurement of polyps with instruments can be more time consuming than visual estimation, and may be associated with some technical difficulties. Therefore, more studies should be conducted to find appropriate and easy methods for the exact measurement of the size of polyps in the future.

Finally, the main advantage of this study was that the authors investigated polyps $6 \mathrm{~mm}$ or more in size, which have not been studied to date. The size of the polyps was overestimated, which resulted in inappropriate surveillance intervals. On the basis of the results, the authors suggested that the polyp size measurement after resection, as recorded in the pathology report, should be used to determine the appropriate timing of subsequent surveillance colonoscopy. Evidently, the measurement of size during pathologic examination may be the most obvious and accurate method.

However, there are no studies on the possible follow-up colonoscopy guidelines according to the pathologically measured polyp size. Most previous guidelines were based on endoscopically measured sizes. In the US guidelines, proper measurement methods were not specified, whereas the UK guidelines use endoscopically measured sizes. Therefore, determining the surveillance colonoscopy interval based on a pathologic size scale requires more research and evidence in the future.

\section{Conflicts of Interest}

The authors have no financial conflicts of interest.

\section{REFERENCES}

1. Zauber AG, Winawer SJ, O’Brien MJ, et al. Colonoscopic polypectomy and long-term prevention of colorectal-cancer deaths. N Engl J Med 2012;366:687-696.

2. Cairns SR, Scholefield JH, Steele RJ, et al. Guidelines for colorectal cancer screening and surveillance in moderate and high risk groups (update from 2002). Gut 2010;59:666-689.

3. Lieberman DA, Rex DK, Winawer SJ, Giardiello FM, Johnson DA, Levin TR. Guidelines for colonoscopy surveillance after screening and polypectomy: a consensus update by the US Multi-Society Task Force on Colorectal Cancer. Gastroenterology 2012;143:844-857.

4. Matsuda T, Chiu HM, Sano Y, Fujii T, Ono A, Saito Y. Surveillance colonoscopy after endoscopic treatment for colorectal neoplasia: from the standpoint of the Asia-Pacific region. Dig Endosc 2016;28:342-347.

5. Atkin WS, Valori R, Kuipers EJ, et al. European guidelines for quality assurance in colorectal cancer screening and diagnosis. First edition--colonoscopic surveillance following adenoma removal. Endoscopy 2012;44 Suppl 3:SE151-SE163.

6. Eichenseer PJ, Dhanekula R, Jakate S, Mobarhan S, Melson JE. Endoscopic mis-sizing of polyps changes colorectal cancer surveillance recommendations. Dis Colon Rectum 2013;56:315-321.

7. Anderson BW, Smyrk TC, Anderson KS, et al. Endoscopic overestimation of colorectal polyp size. Gastrointest Endosc 2016;83:201-208.

8. Leggett $B$, Whitehall V. Role of the serrated pathway in colorectal cancer pathogenesis. Gastroenterology 2010;138:2088-2100.

9. Fennerty MB, Davidson J, Emerson SS, Sampliner RE, Hixson LJ, Garewal HS. Are endoscopic measurements of colonic polyps reliable? Am J Gastroenterol 1993;88:496-500.

10. Margulies C, Krevsky B, Catalano MF. How accurate are endoscopic estimates of size? Gastrointest Endosc 1994;40(2 Pt 1):174-177. 
11. Chaptini L, Chaaya A, Depalma F, Hunter K, Peikin S, Laine L. Variation in polyp size estimation among endoscopists and impact on surveillance intervals. Gastrointest Endosc 2014;80:652-659.

12. Macrae FA, Tan KG, Williams CB. Towards safer colonoscopy: a report on the complications of 5000 diagnostic or therapeutic colonoscopies. Gut 1983;24:376-383

13. Rosen L, Bub DS, Reed JF 3rd, Nastasee SA. Hemorrhage following colonoscopic polypectomy. Dis Colon Rectum 1993;36:1126-1131.

14. Waye JD, Lewis BS, Yessayan S. Colonoscopy: a prospective report of complications. J Clin Gastroenterol 1992;15:347-351.
15. Pham T, Bajaj A, Berberi L, Hu C, Taleban S. Mis-sizing of adenomatous polyps is common among endoscopists and impacts colorectal cancer screening recommendations. Clin Endosc 2018;51:485-490.

16. Gopalswamy N, Shenoy VN, Choudhry U, et al. Is in vivo measurement of size of polyps during colonoscopy accurate? Gastrointest Endosc 1997;46:497-502.

17. Kume K, Watanabe T, Yoshikawa I, Harada M. Endoscopic measurement of polyp size using a novel calibrated hood. Gastroenterol Res Pract 2014;2014:714294. 